\title{
Preliminary design study of Long-life Gas Cooled Fast Reactor With Modified CANDLE Burnup Scheme
}

\author{
Nur Asiah A. ${ }^{1)}$, Merry Yanti ${ }^{1)}$, Zaki Su'ud ${ }^{1)}$, Menik A. ${ }^{1)}$, H. Sekimoto $^{2)}$ \\ 1) Nuclear Physics and Biophysics Research Division \\ Faculty of Mathematics and Natural Sciences \\ Institut Teknologi Bandung \\ ${ }^{2)}$ Research Laboratory for Nuclear Reactors, \\ Tokyo Institute of Technology, Japan \\ e-mail: szaki@fi.itb.ac.id
}

\begin{abstract}
In this paper, preliminary design study of Gas Cooled Fas Reactors with Natural Uranium as Fuel Cycle Input has been performed. Gas Cooled Fast Reactor is slightly modified by employing modified CANDLE burnup scheme so that it can use Natural Uranium as fuel cycle input. The natural uranium is initially put in region 1, after one cycle of 10 years of burn-up it is shifted to region 2 and the region 1 is filled by fresh natural uranium fuel. This concept is basically applied to all regions. In this case the system has been applied to many power level which results relatively flexible discharge burn-up level up from about $20 \% \mathrm{HM}$ to $30 \% \mathrm{HM}$.
\end{abstract}

Keywords: Gas Cooled Fast Reactor (GCFR), Natural uranium, Burnup-cycle

\section{Introduction}

Gas cooled fast reactors are among fourth generation Nuclear Power Plants (NPPs) with hard neutron spectrum characteristics. Such hard spectrum can be utilized to create the reactors system with high breeding capability. In this study the gas cooled reactor system are combined with modified CANDLE burnup scheme ${ }^{1-6)}$ to create long life fast reactors with natural circulation as fuel cycle input. Therefore using this type of nuclear power plants optimum nuclear energy utilization including in developing countries can be easily conducted without the problem of nuclear proliferation. The optimization processes include adjustment of fuel region movement scheme, volume fraction adjustment, core dimension, etc.

As discussed in previous studies, the average burnup level of about 30\% HM or more in general resulted in the optimal design from criticallity point of view. However such burnup level is significantly above current advanced fast reactor material specification. In this study, the long-life gas cooled fast reactors are optimized to reduce average burnup level by employing excellent neutronic characteristics of these reactors.

\section{Calculation Method}

The calculation is performed using SRAC code system (SRAC-CITATION system) and FI-ITBCH1 code, detail explanation can be found in references ${ }^{6-9}$ ). At the beginning we assume the power density level in each region and then we perform the burn-up calculation using the assumed data. The burn-up calculation is performed using cell burn-up in SRAC code which then give eight energy group macroscopic cross section data to be used in two dimensional R-Z geometry multi groups diffusion calculation. The average power density in each region resulted from the diffusion calculation is then brought back to SRAC code for cell burn-up calculation. This iteration is repeated until the convergence is reached. For the safety analysis we adopt the methods we have developed and upgraded.

The reactor cores are subdivided into several parts (regions) with the same volume in the axial directions (See Figure 1) The natural uranium is initially put in region 1 , after one cycle of 10 years of burn-up it is shifted to region 2 and the region 1 is filled by fresh natural uranium fuel. This concept is basically applied to all regions.

\section{Results and Discussion}

Table 1 shows sample design parameters. The reactor power is $550 \mathrm{MWt}$, with axially subdivided into 10 regions. The period of each shuffling period is 10 years. The fuel is nitride type UN-PuN, with natural uranium as fuel cycle input.

Figure 2 shows effective multiplication change during burn-up. The value of effective multiplication constant is monotonously increases. Therefore the important condition for criticality is in the beginning of life (BOL). Figure 3 shows the burn-up history. It shows that at first half of the burn-up history the burnup level is very slowly increases. It is caused by the relatively low flux level in regions 1-5. But after entering regions 6-10 the plutonium accumulation rate significantly increases. Figure 4 shows infinite multiplication change during burn-up history. Consistent with the Figure 3, the slow accumulation of plutonium at half period of burn-up history caused slow increase of infinite multiplication constant. However for the first 10 years the increase of infinite multiplication constant relatively higher than in the period of $10-50$ years. It is caused by the shuffling scheme which put first region near the 10 'th region. 
Figure 5 shows conversion ratio change during burn-up history. At the BOL the conversion ratio is high due to very low enrichment (fresh fuel is natural uranium) but gradually decrease and becoming slightly higher than one at the end of life (EOL).

Figures 6 and 7 shows the U-238 and Pu-239 atomic density change during burn-up history. U-238 atomic density decrease slowly at the BOL and significantly accelerated after half of burn-up history. This is consistent with the results in Figs. 3-5. Pu-239 atomic density increases slowly at the BOL and its change rate significantly increases after half of burnup history when the fuels enters the most active regions (Regions 6-10).

This results shows that gas cooled fast reactors can be designed as nuclear power plant with natural uranium as fuel cycle input. The results is roughly comparable as Pb-Bi cooled NPP.

Table 1. Sample Design Parameter

\begin{tabular}{|l|l|}
\hline Parameter & Value/description \\
\hline Power (MWth) & 550 \\
\hline $\begin{array}{l}\text { Number of equal volume region in } \\
\text { core }\end{array}$ & 10 \\
\hline Sub cycle length (years) & 10 \\
\hline Fuel type & $\begin{array}{l}\text { Natural Uranium, } \\
\text { nitride }\end{array}$ \\
\hline Fuel volume fraction & $65 \%$ \\
\hline Cladding volume fraction & $10 \%$ \\
\hline Coolant volume fraction & $25 \%$ \\
\hline Fuel diameter & $1.2 \mathrm{~cm}$ \\
\hline Coolant type & $\mathrm{He}$ \\
\hline Axial width of each region & $17.5 \mathrm{~cm}$ \\
\hline Active core radial width & $120 \mathrm{~cm}$ \\
\hline Reflector radial width & $50 \mathrm{~cm}$ \\
\hline Reflector axial width & $50 \mathrm{~cm}$ \\
\hline
\end{tabular}

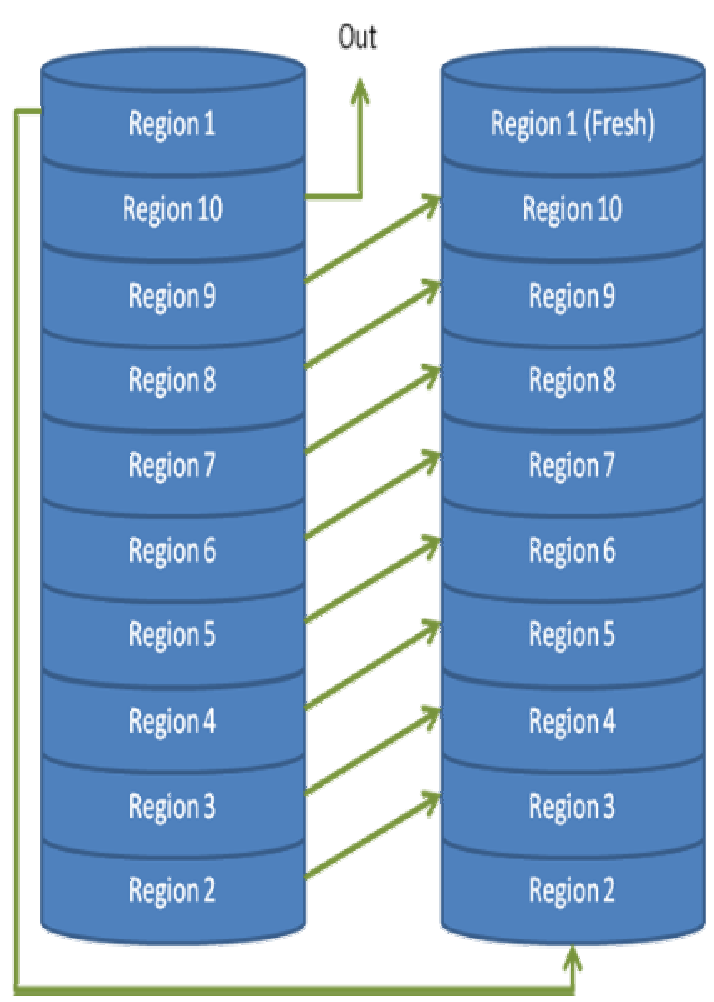

Figure 1. Sub-region division and shuffling scheme

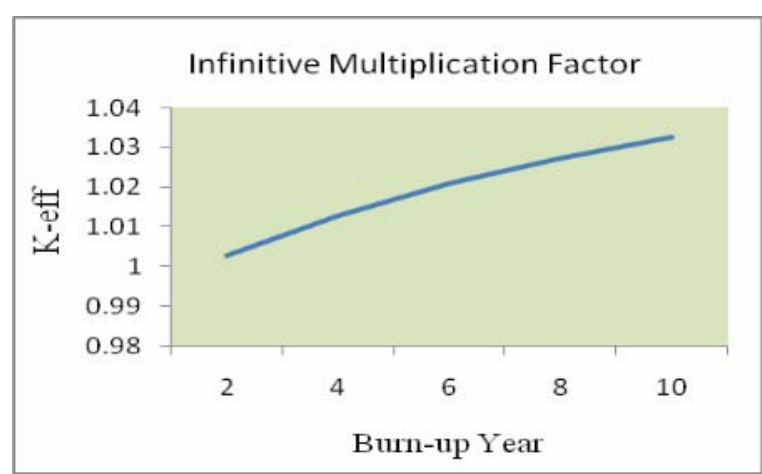

Figure 2 Effective multiplication change during burnup

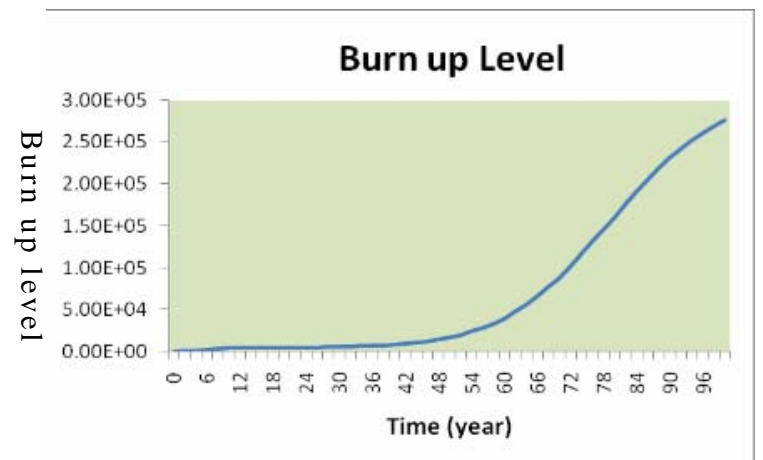

Figure 2. Effective multiplication change during burnup 


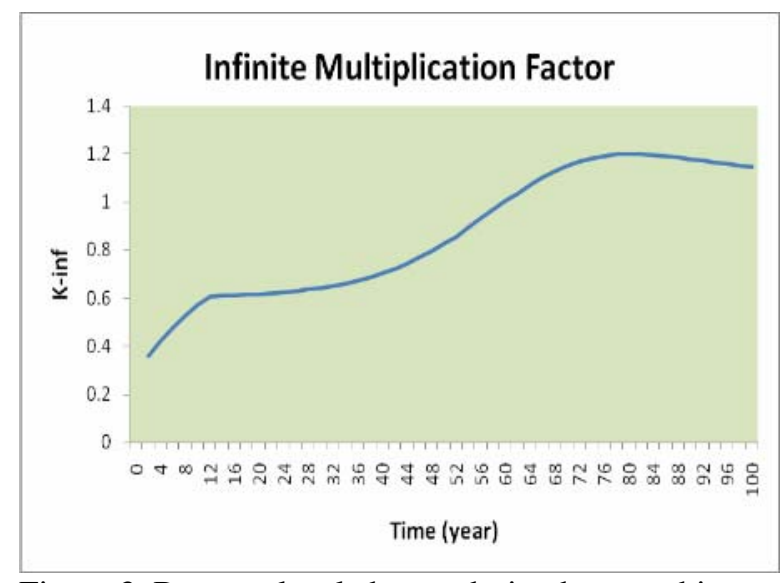

Figure 3. Burn-up level change during burn-up history

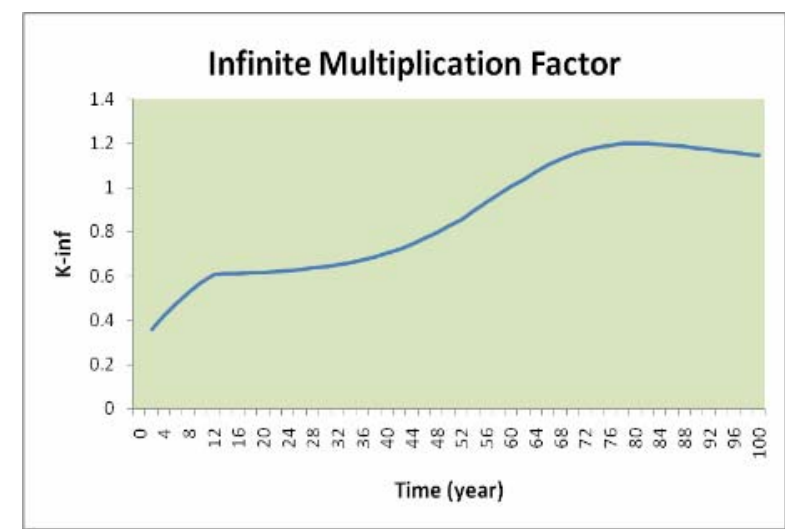

Figure 4. Effective multiplication change during burnup history

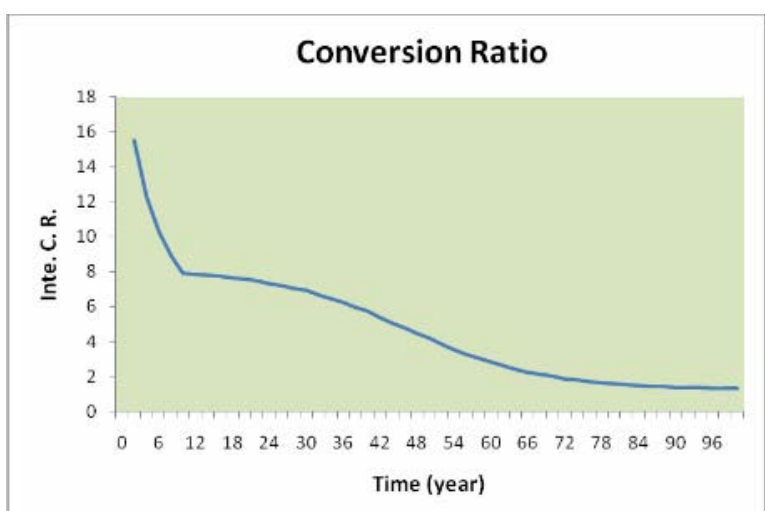

Figure 5. Conversion ratio change during burn-up history

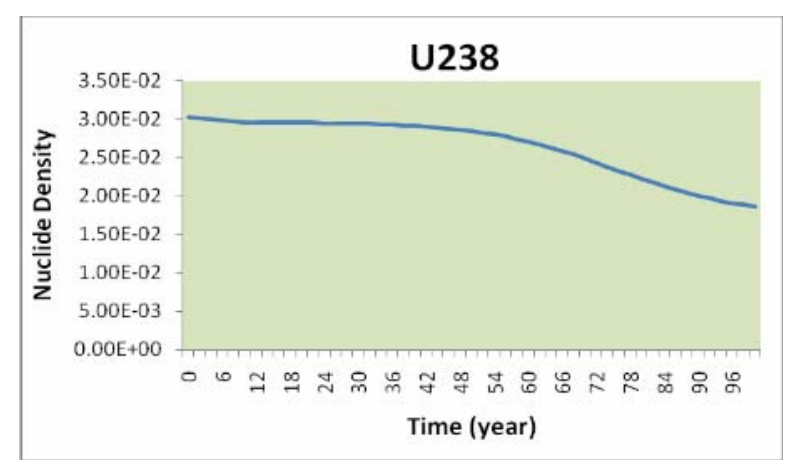

Figure 6. U-238 nuclide density change during burnup history

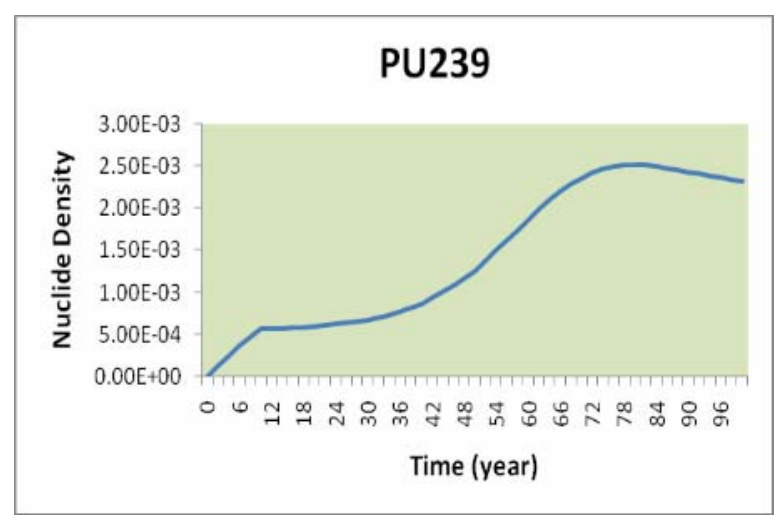

Figure 7. Pu-239 nuclide density change during burnup history

\section{Conclusion}

Preliminary design study of Gas Cooled Fas Reactors with Natural Uranium as Fuel Cycle Input has been performed. Gas Cooled Fast Reactor is slightly modified by employing modified CANDLE burnup scheme so that it can use Natural Uranium as fuel cycle input. In this case the system has been applied to many power levels which give relatively flexible discharge burn-up level up from about $20 \% \mathrm{HM}$ to $30 \% \mathrm{HM}$.

\section{References}

1. H. Sekimoto, Light a CANDLE An Innovative Burnup Strategy of Nuclear Reactors, COE INES, Research Lab. For Nuclear Reactors, Tokyo Institute of Technology, Japan.

2. H. Sekimoto, et al, CANDLE: The New Burnup Strategy, Nucl. Sci. Eng., 139, 1-12, 2001.

3. H. Sekimoto and S. Miyashita, Startup of CANDLE Burnup in Fast Reactor from Enriched Uranium Core, Proc. F $12^{\text {th }}$ n. Conf. on Emerging Nuclear Energy System (ICENES 2005), Aug. 21-26, 2005, SCK.CEN, Mol., Brussels, Belgum, 2005.

4. Y. Ohoka and H. Sekimoto, Application of CANDLE Burnup to Block Type High Temperature Gas Cooled Reactor, Nucl. Eng. Des., 229, 15-23, 2004.

5. Y. Ohoka and H. Sekimoto, Application of CANDLE Burnup to Block Type High Temperature Gas Cooled Reactor for Incenerating Weapon Grade Plutonium, Proc. of GENES 4/ANP 2003, Sept. 15-19, Kyoto, Japan, 2003.

6. Z. Suud and H. Sekimoto, Modified Candle Burnup Schemeand Its Application For Long Life $\mathrm{Pb}-\mathrm{Bi}$ Cooled Fast Reactor With Natural Uranium As Fuel Cycle Input, Proceeding of ICANSE 2007 Conference, November 13-14, 2007, Bandung, Indonesia, 2007.

7. Z. Su'ud et al., Feasibility Analysis of Nuclear Energy System for Developing Countries Which Can Utilize Natural Uranium/Thorium Efficiently Without Embedded Enrichment plant nor Reprocessing plants, ICANSE 2007 Conference, 
13-14 November 2007, Grand Aquila Hotel, Bandung, Indonesia, 2007.

8. Z. Suud, Small and Medium Sized Liquid Metal Cooled Safety Analysis Using Multi Level Complexity Model, $10^{\text {th }}$ Int. Conf. on Nuclear
Safety and Nuclear Education, Obninsk, October 1-5, 2007.

9. K. Okumura et al., SRAC (Ver.2002); The comprehensive neutronics calculation code system, JAERI 2002. 